\title{
Juventude e restaurantes fast food: a dura face do trabalho flexível
}

\author{
Sílvia Maria Fávero Arend \\ Universidade do Estado de Santa Catarina (UDESC)
}

\author{
Antero Maximiliano Dias dos Reis \\ Universidade do Estado de Santa Catarina (UDESC)
}

\section{Juventude e restaurantes fast food: a dura face do trabalho flexível}

Resumo: Neste estudo analisa-se como se operam as relações de trabalho no mundo juvenil a partir das experiências relatadas por trabalhadores e trabalhadoras da rede de restaurantes fast food McDonald's na cidade de Florianópolis, no período entre 2000 e 2007. Constatou-se que o sistema de produção e serviço vigente nesse setor é regido por estratégias idealizadas tanto no fordismo quanto no toyotismo. Este sistema fast food procura forjar um determinado tipo de trabalhador, entendido como "multifuncional", "intercambiável" e "descartável" na medida em que, sob o eufemismo da flexibilização, utiliza-o na quantidade, no lugar e pelo tempo desejado. Para tanto, desenvolve um treinamento específico em que a alta rotatividade destes atendentes não inviabiliza o negócio de restaurantes de comidas rápidas.

Palavras-chave: relações de trabalho, juventude, tempo presente.

\section{Youth and Fast Food Restaurants: the Tough Face of Flexible Labor}

Abstract: This study analyzes how labor relations operate in the world of youth based on the reported experiences of male and female workers in the McDonald's fast food restaurants in the city of Florianópolis from 2000 - 2007. It was found that the production and service system in this sector is guided by Fordist and Toyotist strategies. This fast food system seeks to forge a certain kind of worker, understood as "multifunctional," "interchangeable" and "discardable" to the degree that, under the euphemism of flexibilization, it utilizes labor in the quantity, place and time desired. To do so, specific training is conducted in which the high turnover of these attendants does not make the business of the fast food restaurants unviable.

Key words: labor relations, youth, time present. 


\section{Introdução}

As redes de fast food inserem-se no tempo presente como grandes marcas globais para o consumo em massa (KLEIN, 2006; FONTENELLE, 2002). Tal questão possibilita-nos transitar entre um cenário local e global, observando que o fenômeno da contratação de uma mão de obra juvenil, por parte destas empresas, não é uma característica particular do caso brasileiro. O McDonald's, maior dentre estas redes, é um dos símbolos heurísticos do capitalismo globalizado, tendo em vista que a constituição de sua marca confunde-se com a história do capitalismo moderno, em grande parte, devido à expansão geométrica que teve por diversos países, através do sistema de franquia comercial (FONTENELLE, 2002). Atualmente, no Brasil a rede Mcdonalds possui 1.158 pontos de venda, divididos em 554 restaurantes, 557 quiosques e 50 cafeterias, onde são atendidos diariamente cerca de 1,6 milhão clientes ${ }^{1}$.

Como consequência de uma reorientação das práticas socioculturais relativas à alimentação, os restaurantes de comidas rápidas passaram a ser frequentados em larga escala nos centros urbanos do país e do mundo. O modelo fast food transformouse em um sinônimo de estilo de vida, em que o tempo é exíguo até mesmo para a realização das refeições. $\mathrm{Na}$ esteira da proliferação da indústria de fast food emerge a possibilidade de analisarmos, no mercado de trabalho contemporâneo, as experiências de uma classe trabalhadora em formação, constituindo-se na inserção de milhares de jovens brasileiros, de ambos os sexos, no emprego formal.

No Brasil, os indicadores sobre o mercado de trabalho revelam um quadro dramático no que se refere às taxas de desemprego entre os jovens de 16 a 24 anos de idade. Nesta faixa etária, o número de desempregados é duas vezes superior ao de adultos na mesma condição. A indústria de fast food aparece, então, como importante gerador de empregos para esse exército de mão de obra excedente. Instituições públicas e privadas veêem, nesste setor, um referencial em relação à formação profissional.

Uma parcela significativa da população juvenil brasileira, de acordo com a socióloga Nadya Araujo Guimarães (2005), está presente no mercado de trabalho, seja na busca de emprego, seja no intuito de ascensão social através de melhores ocupações, contrariando os autores que afirmam que o labor não teria um significado central na atual sociedade, sobretudo, entre jovens. O trabalho para os grupos sociais brasileiros de baixa renda é um meio de garantir a sobrevivência, bem como um caminho para melhora das condições de vida. Sendo assim, este confere sentido e orienta percepções, pertenças e práticas individuais ou coletivas.

A inserção dos jovens no mercado de trabalho no Brasil tornou-se um problema para a sociedade em geral e objeto das políticas públicas em particular. De acordo com a pesquisa Perfil da Juventude Brasileira (ABRAMO; BRANCO, 2005), o trabalho é o assunto que mais mobiliza o interesse dos jovens e, no interior deste amplo tema, a referência precípua é a do emprego. Os dados da referida pesquisa demonstram que $30 \%$ dos entrevistados têm uma preocupação direta com a situação do desemprego devido à transitoriedade e insegurança impostas pelo mercado nas últimas décadas do século 20.

\section{Perspectiva metodológica}

Os sujeitos desta pesquisa são os atendentes dos restaurantes Mcdonald's. Foram realizadas 16 entrevistas com ex-funcionários desta cadeia de fast food, dentre os quais, 8 mulheres e 8 homens, todos maiores de 18 anos de idade. Os nomes dos trabalhadores e trabalhadoras juvenis utilizados neste estudo são fictícios, preservando, assim, a identidade dos informantes. O conjunto destes depoimentos orais subsidia a compreensão do cotidiano destas pessoas, no qual o mundo do trabalho adquire especial relevância. Tais entrevistas foram efetuadas a partir da aplicação de um questionário semiestruturado que objetivava, através do testemunho memorial, conhecer trajetórias de vida.

O testemunho memorial permite a observação de trajetórias, eventos e processos, que podem ser elucidados de forma mais densa quando existe a possibilidade de ouvir os atores sociais, especialmente, a história das "pessoas comuns". Para o historiador Paul Thompson (1992), p. 138), a história ganha novas dimensões quando a experiência de vida das pessoas é utilizada como matéria-prima e, em alguns campos, pode resultar não apenas em uma mudança de enfoque, mas também na abertura de novas áreas importantes de investigação. Segundo este autor, a evidência oral permite acessar memórias através de relatos que ganham um significado social. Pode-se supor que a informação oferecida pela evidência da entrevista sobre eventos recentes, ou situações em curso, situa-se em algum ponto entre o comportamento social concreto e as expectativas ou normas sociais da época. Admite-se, em geral, que o processo da memória depende da percepção. Nós a apreendemos em categorias, percebendo como as informações se ajustam, e isso nos possibilita reconstruíla em uma ocasião futura, ou reconstruir alguma aproximação daquilo que compreendemos. O processo de memória depende, dessa forma, não só da capacidade de compreensão do indivíduo, mas também de seu interesse.

A memória passou a fazer parte dos estudos históricos por muitos meios e formas. Estes estudos foram motivados por novas metodologias fundamenta- 
das no esforço de recuperar a experiência e os argumentos daqueles que normalmente permanecem invisíveis na documentação histórica convencional. Além de considerar seriamente estas fontes como evidência não seria demasiado afirmar que a História Oral, cotejada por outros artefatos e "textos", provou-se crucial para o processo de superação das noções convencionais acerca do que vale como história e do que a História pode contar.

Ao situarem a memória simultaneamente como fonte de alternativas e resistências vernaculares ao poder estabelecido e como objeto de manipulação ideológica hegemônica por parte das estruturas de poder cultural e político, os historiadores fizeram muito mais do que simplesmente incorporarem a memória à sua coleção de ferramentas, fontes, métodos e abordagens. A própria memória coletiva vem se convertendo cada vez mais em objeto de estudo: ela tem sido entendida, em todas as formas e dimensões, como uma dimensão da História com uma história própria que pode ser estudada e explorada (FRISCH; THOMSON; HAMILTON, 1996, p. 77).

A psicóloga social Ecléa Bosi (1995) afirma que a memória como reconstrução social depende das relações entre seus portadores e o meio. A memória é, neste sentido, fruto do trabalho de "trazer à tona" em um movimento que aflora certa consciência do estar no mundo. Nesta pesquisa buscamos perceber a relação que as novas gerações instituem com a memória. Dessa forma, é de grande relevância o que o depoente juvenil lembra e seleciona para elaborar sua narrativa. Esta exige um necessário esforço de reconstrução com lembranças de um passado menos longínquo, mas não menos contundente. Lembrar, portanto, não resulta reviver, mas sim refazer, o que, consequentemente, pode fazer-nos duvidar da sobrevivência do evento tal como foi. Por isso, a importância do cruzamento das fontes escritas com as fontes orais, para melhor elucidar tais eventos históricos.

Utilizamos nesta investigação a memória dos jovens, pois consideramos que o vivido, a partir desta idade da vida, expressa-se em determinados valores e práticas e possui importante papel para o indivíduo do tempo presente. A experiência juvenil torna-se significativa para compreendermos uma forma de ser e estar no mundo, que tem caracterizado nas últimas décadas uma cultura de "juvenilização" da sociedade ocidental. A juventude não mais se restringe a faixas etárias pré-determinadas, como bem afirma o sociólogo Luís Antônio Groppo (2000). Para o autor, os critérios etários e os critérios socioculturais acerca da condição juvenil já não mais se conciliaram em determinadas camadas sociais. No que se refere aos trabalhadores e trabalhadoras, atendentes do Mcdonald's, encontramos, por exemplo, menores aprendizes de 14 anos de idade convivendo, tanto no ambiente de trabalho quanto fora dele, com jovens de 24 anos de idade ou mais. Existindo assim, em muitas circunstâncias, um embaralhamento etário.

$\mathrm{O}$ projeto foi submetido ao Comitê de Ética em Pesquisa com Seres Humanos da UDESC, com parecer favorável. Foi solicitado o consentimento livre e esclarecido dos sujeitos entrevistados, a partir de um termo de consentimento para esta publicação, devidadamente assinado pelo pesquisado e pesquisador. Assegurou-se a confidencialidade e a privacidade de seus depoimentos, garantindo a não utilização das informações em prejuízo dos que participassem da pesquisa e observando-se as normas legais e éticas para pesquisa que envolve seres humanos ${ }^{2}$.

\section{Treinamento: a "alma" do negócio fast food}

Cerca de 34 mil funcionários trabalham, atualmente, na rede de fast food Mcdonald's, que anuncia em seu sítio eletrônico ser uma das cinco maiores formadoras de mão de obra no país. A empresa afirma realizar para milhares de jovens brasileiros, todos os anos, o que chama de "sonho do primeiro emprego". Para candidatar-se a uma vaga nos restaurantes Mcdonald's, os jovens de ambos os sexos podem preencher um formulário diretamente em uma loja ou, na web, através do sítio eletrônico da empresa. Os jovens devem ter concluído ou estar matriculados no ensino médio e possuir entre 16 e 24 anos para ingressar como atendentes no McDonald's ${ }^{3}$. Também podem entrar como menores aprendizes, caso tenham entre 14 e 16 anos de idade ${ }^{4}$.

De acordo com o prescrito no sítio eletrônico desta cadeia de restaurantes de comidas rápidas, cerca de $70 \%$ de seus atendentes tiveram sua primeira oportunidade profissional na própria empresa, a qual não exige qualquer experiência laboral anterior. A reduzida faixa etária média dos funcionários do McDonald's indica que a sua oferta de emprego está relacionada à inserção do jovem brasileiro no mercado de trabalho (MCONOMICS, 2005). No ano de 2006, os números percentuais do quadro de funcionários por faixas etárias traduzem tal contexto: acima dos 46 anos de idade o percentual é zero; entre 36 e 45 anos de idade, é de $2 \%$; entre 26 a 35 anos de idade, é de $8 \%$; e o restante, ou seja, $87 \%$ possui menos de 21 anos de idade, sendo que deste total de empregados, $55 \%$ são do sexo feminino (REVISTA ÉPOCA, 2007). A partir deste percentual, a rede McDonald's evoca uma imagem de grande geradora de postos de trabalho para homens e mulheres jovens.

Um ex-trabalhador, Fábio, da rede McDonald's, em Florianópolis, relatou que a procura de um emprego, logo após o término do ensino médio, era-lhe imposta pela necessidade econômica e ocupacional ${ }^{5}$. 
Tal questão demonstra o caráter valorativo do trabalho em determinados contextos socioeconômicos no Brasil. Em sua narrativa, Fábio, infere sobre o motivo que leva o McDonald's a recrutar pessoas mais jovens para o labor nos restaurantes:

Eu tinha terminado o segundo grau e não podia ficar parado. Procurei trabalho com minha avó, vimos no jornal o anúncio do McDonald's, no outro dia a gente foi lá. Eu não tinha quase nada de experiência, já tinha trabalhado uma semana ou duas em outros lugares, mas nada que passasse disso. Acho que eles contratam jovens, porque os jovens não têm muita experiência no mercado de trabalho, aí podem moldar o jeito de ser desse funcionário. Se eles pegam um funcionário mais velho, que vem com 'manias', é mais complicado de lidar'

A partir de sua contratação, os trabalhadores juvenis do McDonald's são introduzidos em um treinamento que busca atingir os fundamentos primordiais da empresa, ou seja, o QSL\&V (KROC; ANDERSON, 1977, p. 97-102). Estes são constituídos a partir dos seguintes princípios: $\mathrm{Q}=$ Qualidade dos Produtos, $\mathrm{S}=$ Serviço Rápido e Cortês, L= Limpeza, Organização e Ambiente Agradável dos Restaurantes e V= Justo Valor para os Produtos. Segundo o jornalista John Love (1996), o padrão QSL\&V é "símbolo universal de performance no ramo de fast food."Ray Kroc (KROC; ANDERSON, 1977), fundador do sistema de franquia comercial, argumenta que seu intuito era construir um modelo de restaurantes que ficasse conhecido pelos alimentos de qualidade e por métodos uniformes de preparação: "nosso objetivo, sem dúvidas, era conseguir vendas contínuas baseadas na reputação do sistema, e não na qualidade de uma única loja ou concessionário." Para que se desenvolvesse tal sistema, foram necessárias a implantação de um programa ininterrupto de treinamento aos concessionários e a inspeção constante de seu desempenho. Neste sentido, a padronização deveria atingir todos os processos, desde o manejo da matéria prima até o produto final, englobando as normas a serem seguidas no atendimento ao cliente.

A indústria fast food, diferentemente de outros segmentos econômicos, é composta por um sistema em que no mesmo espaço há a produção de mercadorias e a prestação de serviço. O sistema de produção fast food, por sua vez, é norteado por estratégias que consubstanciam tanto o modelo produtivo do fordismo/taylorismo quanto o do toyotismo, isto é, o treinamento é um produto da junção destes dois processos. Treinamento e competitividade passaram a ser aspectos imbricados no terreno das organizações na atual ordem econômica mundial. O treinamento deve ser "maleável” e suscetível à absorção de constantes informações sobre o mercado.
O departamento de recursos humanos da rede McDonald's, no Brasil, vem elaborando desde o ano de 2005 um programa de gestão de desempenhos, que visa a formação profissional dos trabalhadores juvenis. Este treinamento deve garantir aos funcionários dos restaurantes a habilitação necessária para alcançar resultados efetivos segundo os princípios da empresa, bem como provocar impacto positivo nos lucros. Este processo de treinamento procura formalizar, acompanhar e controlar os resultados individuais. Os índices dos níveis de competência de cada um dos funcionários dos restaurantes, advindos dos resultados do treinamento, servem para diferenciálos nos processos futuros relativos às promoções ${ }^{7}$.

O modelo do fordimo-taylorismo nos restaurantes McDonald's pode ser visualizado, primeiramente, na supervisão constante dos trabalhadores, pois a instituição de um padrão nos procedimentos é a fórmula essencial aplicada pela empresa para atingir mais rapidamente resultados positivos. Através dos modelos padronizados de produção e serviço racionalizamse as atividades dos funcionários. Nos circuitos ou nas áreas, como são chamados os locais de labor, os jovens devem desenvolver sincronizadamente as tarefas: se um dos atendentes, posicionado em uma determinada função na área de produção ou serviço, atrasar em sua atividade, não haverá um ritmo constante na elaboração dos sanduíches, o que impedirá o fluxo de produção. Por exemplo, no circuito 4:1, área onde se produz o sanduíche "Quarterão", a organização dos pães é regulada nos 30 segundos quando soa o sinal sonoro do timer. Após este período, os pães devem ser rapidamente condimentados, aos 70 segundos o funcionário da chapa deve retirar as carnes e colocá-las nos sanduíches, preparando uma próxima rodada que será efetuada aos 80 segundos (REVISTA MCNEWS, 2007, p. 16). Todos estes movimentos são cronometrados através da utilização do timer, sendo constantes e ininterruptos para que haja uma produção em larga escala, a fim de atender a alta demanda dos consumidores. Uma jovem trabalhadora relata a sua percepção sobre as relações de trabalho e o ritmo de produção de um restaurante do McDonald's de Florianópolis:

O relacionamento é aquela coisa meio mecânica, passam o que tu tem que fazer e o que é cobrado de ti com o teu colega. É o procedimento padrão, não se deve falar nada que não seja sobre o trabalho. $\mathrm{O}$ treinamento então é o ' $o k$ obrigado' e o 'retifica', porque a cozinha é muito barulhenta, assim a comunicação padrão serve para que o lanche saia no tempo certo. Em alto movimento, o ritmo é forte, é veloz, tem que ter agilidade, o barulho das máquinas da cozinha é misturado ao som das vozes, é um falando com o outro ao mesmo tempo. A pessoa da produção tem que manter o chamado de lanches para man- 
ter os níveis da estufa. As pessoas falam alto e ainda tem mais o barulho dos clientes no balcão e no salão, às vezes rola um stress. $\mathrm{O}$ ambiente é muito estressante, a gente está ali trabalhando com coordenação e agilidade, não pode errar, não pode perder um lanche. Quando acontece de errar em um lanche especial, dá muita gritaria, o gerente já vem gritando com o funcionário, tem gente que chora, que sai meio tonta de não conseguir dormir, de ter pesadelo com a adrenalina muito alta9 .

Além de fabricar os sanduíches, o atendente do McDonald's deve limpar constantemente as áreas onde executa suas tarefas. As chapas, por exemplo, circuitos em que as carnes são cozidas, a cada 10 minutos devem ser higienizadas. Um jovem refere-se a esta questão da seguinte forma: "tínhamos que estar sempre limpando, mesmo quando já estava limpo, era para não ficar parado"10. Neste ritmo de trabalho de pressupostos tayloristas, a empresa quer usufruir cada segundo pago ao funcionário. Assim, os trabalhadores devem executar a limpeza de suas áreas constantemente. Quando o movimento de vendas estava baixo, alguns funcionários eram retirados de seus postos de trabalho para a realização de tarefas de limpeza, chamadas de secundárias. A higiene nos restaurantes McDonald's constituiu-se em um discurso de valor, sendo parte fundamental do padrão QSL\&V. Na narrativa a seguir, podemos verificar que o trabalhador juvenil deve ser multifuncional também em relação à limpeza. Eis as palavras de Cristina:

O atendente, ele está ali para fazer sanduíches, atender o cliente e fazer a limpeza. Não tem uma equipe de faxineiras para a limpeza, é o atendente quem faz tudo. Pode estar limpando o banheiro, estar na cozinha, estar como caixa ou estar lá fora compactando lixeiras, limpando o piso, as paredes, os jardins, cortando e tirando o mato do estacionamento.

No que se refere ao modelo toyotista de produção, o just-in-time apresenta-se como ponto fundamental no sistema fast food, buscando a redução dos estoques, a produção no tempo exato e em um ritmo predeterminado de acordo com as vendas. Este modelo tem por objetivo técnico produzir somente o necessário, ou seja, o que será comercializado imediatamente (MELLO, 1998, p. 273). Neste processo vinculado diretamente ao fluxo mercadológico, não há grandes estoques de matéria prima e nem de produto final. As alterações que ocorreram a partir dos anos 1980 , primeiramente, foram no sentido de criar uma produção mais enxuta. Com o advento da microeletrônica e da informática na produção e no serviço, os equipamentos das indústrias de fast food foram substi- tuídos, adotando-se através dos computadores formas mais práticas e eficazes de gerir o sistema.

\section{Trabalho fast-food: a experiência da desregulamentação}

Os trabalhadores e trabalhadoras, nas duas últimas décadas do século 20, têm experimentado a insegurança em função dos contratos de trabalho temporário, que substituíram completamente a perspectiva de um emprego seguro (KLEIN, 2006). Sob o eufemismo da flexibilidade, a carreira sem interrupção foi bloqueada, e, como consequência, as pessoas são constantemente obrigadas a se retirar de seus postos de trabalho (SENNETT, 2004). A flexibilização das relações de trabalhado juvenis é uma mudança que consideramos significativa neste novo paradigma. Seu ideário traz à luz o aprofundamento da desregulamentação das relações de trabalho e, é nesta lógica, de precariedade, que os jovens trabalhadores inserem-se como atendentes dos fast food no mercado formal.

Na cidade de Florianópolis, quando se aproxima o verão, período em que há maior afluxo de vendas, os restaurantes McDonald's contratam um grande contingente de funcionários. Logo que termina a estação, muitos destes trabalhadores são imediatamente demitidos e outros saem do emprego por conta própria em busca de um trabalho que lhes possibilite um maior reconhecimento. Sob a lógica do trabalho temporário, pode ocorrer ainda a dispensa do dia de trabalho, pois, se não houver um número de vendas suficientes para aquele período, o funcionário é dispensado antes do término de seu turno. Ou seja, o funcionário se desloca de casa para o trabalho, veste seu uniforme, posiciona-se na área de trabalho e, depois de algum tempo, se o consumo é pequeno, o gerente o dispensa. Observemos que o just-in-time está posto não apenas para os produtos ou máquinas, mas também para homens e mulheres.

O salário pago a estes jovens é relativo às suas horas efetivamente trabalhadas. $\mathrm{O}$ contrato de trabalho reza que a jornada de trabalho não é superior a 44 horas, nem inferior ao mínimo de 8 horas. Nesse processo deve ser observado também o limite mínimo de 11 horas consecutivas de descanso, entre uma jornada e outra. Há ainda, o descanso de 24 horas consecutivas por semana de trabalho. O discurso veiculado pela empresa é de que esta visa adequar este horário de trabalho aos estudos, às atividades de lazer, ou até mesmo a outra atividade profissional destes jovens ${ }^{11}$.

Um atendente que desenvolvesse suas atividades em um restaurante McDonald's em Florianópolis, em abril de 2005, receberia por hora a importância de R\$ 1,46 reais. Devido à cláusula das 8 horas semanais 
mínimas e diante da possibilidade de não haver movimento durante o mês, este trabalhador poderia retornar para sua casa quase todo o dia com poucas horas de trabalho, para que não onerasse o Índice de Produtividade $^{12}$. Este nunca deve exceder ao projetado pelos consultores da rede fast food. Assim, se o trabalhador retornasse para o seu lar com apenas poucas horas de trabalho e se ficasse estabelecido para o mesmo duas folgas por semana, viria receber naquele mês um salário muito menor que o mínimo. No depoimento seguinte, temos o relato de uma trabalhadora que ingressou nos restaurantes McDonald's na função de atendente e desligou-se da empresa depois de três anos, quando trabalhava como coordenadora administrativa. Seu salário no período em que ela permaneceu como funcionária sofreu uma variação muito pequena, tendo em vista o tempo em exerceu suas atividades. Ela discute a possibilidade de uma legislação que não permita o salário ser pago por hora, afirmando que deveria haver uma maior atuação do sindicato ao qual os funcionários do McDonald's estão afiliados.

Eu entrei ganhando R $\$ 1,10$ e sai depois de três anos e quatro meses de serviço com $\mathrm{R} \$ 2,50$ por hora. Para começar a ganhar melhor no McDonald's, demora muito. Pra ti conseguir uma promoção é bem difícil e o dissídio da categoria, vinculado ao sindicato de bares e restaurantes, sempre era pago com atraso. As pessoas diziam que no Mc não deveria haver o pagamento por hora, a hora não é um padrão. Tu não pode entrar no $\mathrm{Mc}$ pensando o quanto tu vai ganhar, tanto é que de uma cidade para outra tem uma grande diferença. Por exemplo, em Florianópolis tu ganha mais que em Joinville, mas menos que em Balneário Camboriú. Os salários poderiam melhorar se os sindicatos se empenhassem mais, seria melhor ter um salário fixo, previsível. Quando eu trabalhava lá, eu nunca sabia o quanto que ia ganhar no final do mês. Aúnica coisa que tinha certeza, e que podia contar com dinheiro fixo do Mc, era o adiantamento, que vinha no dia 20, e o dinheiro do 'passe' (vale transporte), que vinha no dia primeiro, estes a gente sabia quanto vinha, porque o salário do dia 5 a gente nunca sabia. Às vezes a gente fazia uma base somando as horas e achava que ia receber um tanto, aí chegava na hora o valor era bem diferente, bem menor. Eu acho que deveria ter um salário fixo. Mas, com um salário fixo, os consultores falam que o funcionário teria que ficar somente em uma área, por exemplo, no caixa, aí já teria que pagar quebra de caixa, aumentando os custos para empresa ${ }^{13}$.

Não há um sindicato específico dos trabalhadores dos fast food, seu vínculo é com o sindicato de bares e restaurantes. Em geral, os funcionários pro- curam este sindicato apenas quando necessitam homologar o contrato de trabalho, como é o caso de muitos atendentes dos restaurantes McDonald's em Florianópolis. Semelhante processo ocorre na cidade de Porto Alegre:

\begin{abstract}
O alto índice de rotatividade da empresa é em torno de $50 \%$. No Sindicato dos Empregados em Hotéis, Bares, Restaurantes e Similares, as homologações de funcionários do McDonald's, que reúnem grupos de 20 a 30 jovens de cada vez, são realizadas três vezes por semana (REVISTADINHEIRO, 2000,p. 45).
\end{abstract}

Outro ponto relativo às desregulamentações promovidas no McDonald's está relacionado ao intervalo de descanso que, como afirmamos, deve ser de 11 horas entre uma jornada e outra. Porém, de acordo com alguns depoimentos, existiram casos em que esta cláusula era descumprida. Se um trabalhador desenvolvesse atividade de fechamento da loja após as 24 horas e, por ser maior de idade, tivesse de realizar o recebimento de mercadorias (atividade proibida para menores devido ao peso das caixas dos produtos), este descansaria menos que o prescrito na legislação. Os trabalhadores e trabalhadoras juvenis menores de idade, em períodos com maior movimento de vendas, excediam o horário de trabalho limite, que era às 22 horas. Uma das lojas de Florianópolis, no dia 20 de fevereiro de 2003, foi notificada pelo Ministério do Trabalho, Sistema Federal de Inspeção, em função da seguinte infração:

\begin{abstract}
Manter empregado com idade inferior a 18 anos prestando serviço em horário noturno. Segundo o histórico: foi verificado três menores que prestavam serviço, no horário de nossa visita, que se estendeu das 22:15 h até as 23:20 h. Segue: Descrição Ementa/ NR: "prorrogar a duração normal da jornada de trabalho do empregado com idade inferior a 18 anos, sem convenção de acordo coletivo de trabalho. Nesta situação 1) Cláudia A., D/N.: 27/08/86 que no dia $12 / 02 / 03$ trabalhou das $11: 14$ h às $15: 21$ h e das $16: 23$ h às 23:20 h quando deixamos o local, 2) Cláudia B., D/N.: 19/08/85, que trabalhou no dia 12/02/03 das 11:06 h às 15:24 h e das 16:25 h às 23:20 h, 3) Cláudia C., D/N.: 22/03/87, que trabalhou no dia 12/02/03 das $11: 12 \mathrm{~h}$ às $16: 15 \mathrm{~h}$ e das $17: 14 \mathrm{~h}$ às $23: 20 \mathrm{~h}$, obs.: foi usado como elemento de convicção o controle de ponto de $11 / 02 / 03$, porque a empresa não disponibilizou o ponto de 12/02/03, e o mesmo espelha a jornada. Art. 413 inciso I da CLT ${ }^{14}$.
\end{abstract}

No depoimento abaixo, o trabalhador ressalta a dificuldade que a empresa encontrava para contratar pessoas maiores de idade, tendo por isso a necessidade de utilização de mão de obra de menores de idade, após às 22 horas. 
Em alto movimento tinham poucos funcionários, na verdade o Mc não conseguiu contratar um quadro suficiente e os menores ficavam trabalhando até umas 22:30h. Sempre tinha um atraso para estes menores irem embora ${ }^{15}$.

Segundo a legislação trabalhista, o empregador deve apresentar com antecedência de uma semana a escala com as horas de trabalho e as atividades definidas. O trabalhador, por sua vez, deve cumprir o que nela está estabelecido. $\mathrm{O}$ contrato de trabalho do McDonald's prevê a normatização desta escala. Contudo, a escala era recorrentemente descumprida, sendo bastante comum que o número de horas trabalhadas fosse menor. De acordo com os depoimentos de alguns jovens, somente no próprio dia de trabalho era divulgada a informação sobre o número de horas a ser executado e a tarefa do dia.

Os horários de intervalo, muitas vezes, não eram cumpridos em sua totalidade. De acordo com o depoimento de alguns funcionários, havia a solicitação de que os mesmos não batessem o cartão ponto ao retornar em área antes do término do intervalo (break). Esta lógica ia ao encontro da política do McDonald's de economia de horas, especialmente as horas extras. Roberto e Paulo afirmam o seguinte:

Quando outros funcionários tinham que ir embora, eles (os gerentes) pediam pra eu voltar. Daí eu batia o cartão ponto e voltava em área. Mas já pediram pra eu não bater o cartão, que depois eles davam mais um tempinho (de intervalo). Porque a gente não podia trabalhar mais horas, pois a meta era 8 horas (em alta temporada) por dia e nada mais... Então, se a gente voltasse (antes do término do break) e saísse no horário certo (para ir embora), seria hora extra, eles não queriam pagar a mais pra gente ${ }^{16}$.

Muitas vezes, estava lá sentadinho descansando e vinha o gerente: 'vamos, vamos, encheu o balcão!' Então eu ia lá correndo e ajudava sem bater o cartão, só pra fazer uma moral com o gerente, pra tentar 'subir' de cargo, depois eu ia pro descanso de novo. Geralmente, a gente ganhava um sunday de sobremesa ${ }^{17}$.

Podemos perceber nos depoimentos que, algumas vezes, as horas extras eram pagas com lanches ou sobremesas. O gerente oferecia aos atendentes um produto alimentício do restaurante no intuito de retribuir-lhes o trabalho executado extra em seu período de descanso. Eventualmente acontecia de chamarem um funcionário que estava de folga para trabalhar, devido à falta de alguém ou grande afluxo de clientes. Em seu relato a trabalhadora afirma que, o intervalo, muitas vezes, era insuficiente para uma refeição adequada, mas o pior era ser chamada nos dias em que estava de folga. Eis as suas palavras:

Tu está bem tranquila, já trabalhou umas cinco horas, mal comeu, aí te chamam pra voltar a trabalhar. Isso revolta qualquer um, mas o pior de tudo é ser chamada num dia de folga para trabalhar. Tu espera sete dias pra folgar e aí te chamam. Eu tinha uma colega no primeiro ano em 2003, que trabalhava das 11 às 23 horas. Depois de oito horas que ela trabalhava e descansava uma hora, ela tinha um intervalo de 15 minutos que não batia o cartão. Naquela época ela ainda ganhava horas extras. Agora não pode mais fazer isto, as horas extras estão proibidas. Já aconteceu caso do gerente pedir para não bater o cartão, só depois de completar uma hora, ou dizer: 'segura um pouquinho aí pra mim, que eu não posso exceder as horas'. Porque tem uma quantidade de horas que a loja pode fazer por mês, eu não sei explicar direitinho de onde vem esta determinação do corte de horas, mas eu sei que é feito uma base de anos anteriores. Eles veem pelo movimento de vendas e fazem um cálculo de quantos funcionários são necessários para trabalhar naquele período. Pode acontecer um movimento inesperado naquele dia, aí tu tem que chamar mais um funcionário, mesmo assim, não pode exceder as horas. Aí o gerente te chama e ele te dá uma sobremesa extra, um sanduíche extra pra ti trabalhar aquele tempinho ali, sem estar de cartão batido, tu é pago com um lanche como agrado ${ }^{18}$.

\section{Em busca de um futuro melhor}

Segundo os dados apresentados pela empresa, no Brasil, no ano de 2005, foram recebidos 37.000 currículos, sendo admitidos 22.368 funcionários, demitidos 5.509 e promovidos 3.839 (REVISTA ÉPOCA, 2007). Estas promoções encontravam-se distribuídas na ordem hierárquica entre os cargos de instrutores, coordenadores, técnicos de manutenção, gerentes de plantão, gerentes operadores e gerentes de restaurante. A grande rotatividade de funcionários nos restaurantes da rede permite que surjam constantemente vagas para promoção, que, em geral, são em maior número para os cargos de instrutores. Este é o cargo subsequente na hierarquia ao de atendente que está na base da organização. De acordo o discurso veiculado pela empresa, a promoção é conquistada pelo funcionário através de um esforço particular resultante de seus estudos em relação às normas e procedimentos, proporcionando o aprimoramento profissional ${ }^{19}$.

Conforme pesquisa da própria empresa, um dos pontos mais valorizados pelos funcionários da rede McDonald's no Brasil, é o desenvolvimento profissi- 
onal, tendo $76 \%$ de preferência dos trabalhadores. Logo depois, com $15 \%$, está o item qualidade de vida, seguido pelo fator remuneração e benefícios com 5\% e, por fim, a estabilidade no trabalho que aparece com 4\% (REVISTA ÉPOCA, 2007). Estes percentuais demonstram o quanto os atendentes buscam "subir" de cargo dentro da empresa. Tais objetivos estão vinculados tanto à melhoria econômica, quanto à possibilidade de alcançar status social de maior reconhecimento através de uma promoção.

Com frequência, o periódico mensal, a Revista McNews, maior instrumento de comunicação interna da rede, publica casos de empregados que obtiveram êxito diante de prêmios e promoções. A partir da edição número 98 de 2006, a revista passou a editar uma seção chamada "Minha História", na qual, são veiculados depoimentos "de sucesso" dentro da rede McDonald's, tais como o deste consultor de mercado:

\begin{abstract}
Iniciei minha carreira no McDonald's quando ainda era adolescente. Acredito que minha história dentro da empresa possa ser um exemplo para milhares de funcionários. Comecei a trabalhar em 1993, como atendente e passei por todos os cargos do restaurante até chegar a consultor de mercado. Eu atribuo minhas conquistas ao fato de estar sempre pronto a colaborar, fazer tudo com o sentimento de perfeição, não reclamar e não falar mal dos outros, estudar sempre, ter muita garra e vontade de vencer, e acima de tudo AMAR o que faço (REVISTA MCNEWS, 2007, p. 16).
\end{abstract}

Segundo o depoimento oral de Cláudia, ao obter uma promoção para coordenadora, por algum tempo teve de acumular as "antigas" atividades de instrutora. Pois, dentre os atendentes escolhidos para disputar as vagas de instrutores, nem todos eram promovidos. De acordo com esta funcionária, em algumas lojas de Florianópolis o número de atendentes que alcançava tal promoção ficava abaixo da demanda. Esta prática apresentava-se recorrente na empresa que, ao disponibilizar uma vaga, selecionava um número bem maior de funcionários para disputá-la.

Como coordenadora eu praticamente continuei treinando, nunca tinham instrutores, o pessoal não aguentava e ia embora. Ficavam enrolando tanto a pessoa dizendo que ela ia 'subir', que ia ser promovida e aí distribuíam dez Planos de Desenvolvimento de Instrutores (PDI) entre os funcionários, sen- do que tinham poucas vagas. Obrigavam os caras a treinarem os novatos e, no final, promoviam só três, os outros iam saindo desiludidos, a maioria saía por causa disso ${ }^{20}$.

Conforme havíamos mencionado, as trabalhadoras são em maior número dentro da rede McDonald's, na proporção de $55,4 \%$ do total. Contudo, quando se trata dos cargos de chefia este número se inverte. Em 2005, em todo o Brasil, os cargos de chefia eram num total de 1.327 , sendo $62 \%$ deles ocupados por homens, enquanto que os $38 \%$ restantes eram postos ocupados por mulheres (REVISTA ÉPOCA, 2007). A jovem Carolina relata a experiência de quem disputou uma vaga esperando ser promovida para instrutora (o que de fato não se concretizou). Ela ressalta que as redes sociais estabelecidas no interior dos restaurantes McDonald's podiam facilitar o percurso de uma ascensão de cargo. Podemos verificar que a companhia se utilizava estrategicamente da disputa, e ao incentivá-la obtinha dos concorrentes maior produtividade.

Eu acho que a gente espera demais uma promoção, que muitas vezes não vem. Acho que a gente tem que ser bem mais 'amigo' dos gerentes, do que um bom funcionário que realize suas tarefas. A gente sente, querendo ou não, fica pensando, trabalhou muito e não foi reconhecida. É decepcionante, tu deu mais o 'teu sangue' por aquilo e não foi recompensada ${ }^{21}$.

De acordo com o depoimento da jovem, era possível observar mudanças significativas naqueles trabalhadores que eram promovidos, pois absorveriam com maior facilidade o "espírito de competição" que a companhia procurava imprimir para atingir resultados positivos. Ainda, segundo ela:

Vários colegas ficavam diferentes depois de promovidos, ficavam pessoas com mais expectativas de prosseguir no caminho das promoções. Acabavam se tornando pessoas frias, passando por cima de ti pra chegar ao objetivo.

\section{Considerações finais}

A possível mobilidade dentro da rede McDonald's é muito valorizada entre os atendentes e extrema- 
mente propagandeada pelos meios de comunicação internos da empresa ${ }^{22}$. Traduzindo-se na capacidade de disputar as restritas vagas aos cargos superiores, esta mobilidade vincula-se ao ideário de eficiência. Os trabalhadores devem "incorporar" a visão que a empresa procura transmitir para o seu público consumidor, que é de agilidade e presteza na produção e no serviço. Para o sistema fast food, o corpo jovem é determinante, pois apreende com destreza e rapidez uma série de informações e técnicas de produção. É ainda visibilizado em sua salubridade, podendo suportar com disciplina uma extenuante carga de trabalho.

Este sistema fast food procura forjar um determinado tipo de trabalhador que possui as seguintes características: "multifuncionais", "intercambiáveis" e "descartáveis". O grande contingente de jovens desempregados é conveniente para esta rede de comidas rápidas, que se ocupa de parte deste exército excedente, podendo "adaptar" rapidamente o trabalhador ao seu padrão de produção e serviços, difundindo assim para a sociedade brasileira uma imagem positiva das relações de trabalho no âmbito juvenil. Tratase de uma situação ambígua diante do drama do desemprego, pois muitos trabalhadores juvenis submetem-se à precarização do labor, tendo como horizonte a conquista de um lugar "ao sol" nesta sociedade.

\section{Referências}

ABRAMO, H. W.; BRANCO, P. P. M. (Org.). Retratos da juventude brasileira: análises de uma pesquisa nacional. São Paulo: Fundação Perseu Abramo, 2005. p. 369-447.

BOSI, E. Memória e sociedade. Lembrança de velhos. São Paulo: Companhia das Letras, 1995.

BRASIL. Presidência da República. Subchefia para Assuntos Jurídicos. Emenda Constitucional n. 20, de 15 de dezembro de 1998. Disponível em: <http:// www.planalto.gov.br/ccivil_03/constituicao/emendas/emc/ emc20.htm>. Acesso em: jul. 2005.

. Lei n. 8.069, de 13 de julho de 1990. Disponível em: $<$ http://www.planalto.gov.br/ccivil/ LEIS/L8069.htm>. Acesso em: jul. 2005.

. Lei $n .10 .097$, de 19 de dezembro de 2000. Disponível em: $<$ http://www.planalto.gov.br/ ccivil_03/LEIS/L10097.htm>.Acesso em:jul. 2005.

FONTENELLE, I. A. O nome da marca. McDonald's fetichismo e cultura descartável. São Paulo: Boitempo, 2002.

FRISCH, M.; THOMSON, A.; HAMILTON, P. Os debates sobre memória e história: alguns aspectos internacionais.
In: FERREIRA, M. de M.; AMADO, J. (Org.). Usos e abusos da História Oral. Rio de Janeiro: Fundação Getúlio Vargas, 1996. p. 65-91.

GUIMARÃES, N. A. Trabalho: uma categoria chave no imaginário juvenil. In: ABRAMO, H. W.; BRANCO, P. P. M. (Org.). Retratos da juventude brasileira: análises de uma pesquisa nacional. São Paulo: Fundação Perseu Abramo, 2005, p. 149-174.

GROPPO, L. A. Juventude. Ensaio sobre sociologia e história das juventudes modernas. Rio de Janeiro: Difel, 2000.

KROC, R.; ANDERSON, R. Deu certo! Como nasceu, cresceu e prosperou a McDonald's. Rio de Janeiro: Record, 1977.

KLEIN, N. Sem logo. A tirania das marcas em um planeta vendido. Rio de Janeiro: Record, 2006.

LOVE, J. F. McDonald's. A verdadeira história do sucesso. Rio de Janeiro: Bertrand Brasil, 1996.

MCONOMICS 2005. Uma incrível viagem pela cadeia produtiva do Big Mac. Relatório sobre o impacto econômico do McDonald's no Brasil. São Paulo: GVconsult, 2005.p. 25.

MELLO, P. J. S. Globalização e reestruturação produtiva: do fordismo ao toyotismo. In: ARRUDA JÚNIOR, E. L. de; RAMOS, A. Luiz. (Org.). Globalização, neoliberalismo e o mundo do trabalho. Curitiba: IBEJ, 1998, p. 260- 284.

REVISTA DINHEIRO. McDonald's apuros de um patrão americano. São Paulo: Editora Três, n. 127, p. 45, 2 fev. 2000.

REVISTA ÉPOCA. As 100 melhores empresas para trabalhar: tudo o que você precisa saber para escolher o seu próximo emprego. São Paulo: Globo, 2007.

REVISTA MCNEWS. Assessoria de Comunicação. São Paulo: Publicon. Mensal, n. 98, jan. 2007.

SENNETT, R. A corrosão do caráter. As consequências pessoais do trabalho no novo capitalismo. Rio de Janeiro: Record, 2004.

THOMPSON, P. A voz do passado. História Oral. Rio de Janeiro: Paz e Terra, 1992.

\section{Notas}

1 Disponível em: $<$ http://www.mcdonalds.com.br>.Acesso em: 31 jul. 2008. 
2 Declaração de Helsinki(1975, revisada em 1983 eResoluções do Conselho Nacional de Saúden. 196, de 10/10/96 en. 251, de $07 / 08 / 97$.

3 Disponível em: $<$ http://www.mcdonalds.com.br $>$.Acesso em: 31 jul. 2008.

4 Ver:EmendaConstitucionaln. 20, de 15 de dezembro de 1998 (BRASIL, 1998). A referida emenda passa a enquadrar os jovens que possuem entre 14 e 16 anos na situação de aprendizes. Verainda: Lein. 8.069, de 13 de julho de 1990 eLei n. 10.097, de 19 de dezembro de 2000, esta última lei altera dispositivos da Consolidação das Leis de Trabalho (CLT) (BRASIL, 1990,2000).

5 As entrevistas com estes 16 jovens foram realizadas por Antero Maximiliano Dias dos Reis, pesquisador do grupo Relações de Gênero e Família (LABGEF/UDESC).

6 Fábio, 23 anos de idade. Entrevistado em 20 de março de 2006.

7 Guia do Funcionário. Sistema de Gestão Desempenho. RH McDonald's do Brasil. Out. 2005.p. 5.

8 Estas duas expressões são utilizadas, de forma obrigatória, por estes trabalhadores juvenis durante o labor nos restaurantes da rede McDonald's.

9 Cristina, 21 anos de idade. Entrevista realizada nos dias $13 \mathrm{e}$ 14 de março de 2006.

10 Gabriel, 18 anos de idade. Entrevista realizada no dia 2 de outubro de 2007.

11 Contrato de Trabalho da empresa McDonald's.

12 Índice de Produtividade(IP): cálculo realizado que divide o volume de vendas pelo número de horas trabalhadas. Transações Comerciais (TCs): cada cliente que de fato passe pelo caixa e compre algo é considerado um número do cálculo.

13 Cristina, antes citada.

14 Ministério do Trabalho. Sistema Federal de Inspeção do Trabalho, documento den. 009328823, Florianópolis 20 fev. 2003.

15 Roberto, 19 anos de idade. Entrevista realizada em 20 de marçode 2006.

16 Idem

17 Paulo, 18 anos de idade. Entrevista realizada em 20 de março de2006.

18 Cristina,já citada.
19 Informação disponível em: <http://www.mcdonalds.com.br.>. Acesso em: 11 jun. 2008.

20 Cláudia, 22 anos de idade. Entrevista realizada em 10 de novembro de 2007.

21 Carolina, 19 anos de idade. Entrevista realizada em 27 de marçode 2006

22 O melhor exemploéa Revista McNews.

\section{Sílvia Maria Fávero Arend}

smfarend@gmail.com

Doutorado em História pela Universidade Federal do Rio Grande do Sul

Professora do Departamento de História e do Programa de Pós-Graduação em História da Universidade do Estado de Santa Catarina (UDESC)

Coordenadora do Laboratório de Relações de Gênero e Família (LABGEF/UDESC)

\section{Antero Maximiliano Dias dos Reis} antero.reis@bol.com.br Mestrado em História pela UDESC Participante do grupo de pesquisa Relações de Gênero e Família (LABGEF/UDESC)

\section{UDESC}

\section{Centro de Ciências Humanas e da Educação}

Laboratório Relações de Gênero e Família

Avenida Madre Benvenuta, 2007

Florianópolis - Santa Catarina - Brasil

CEP: 88035-001 